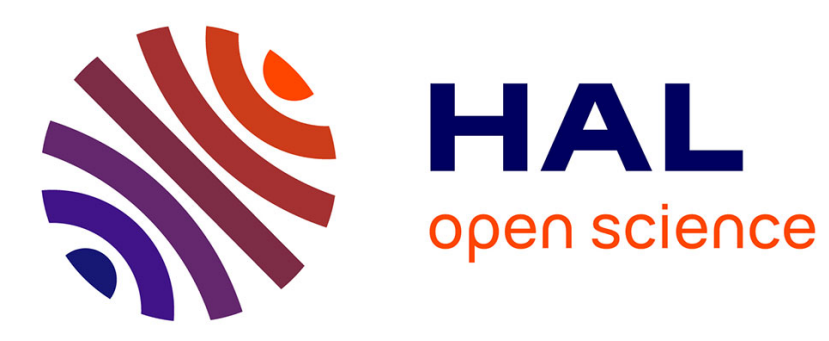

\title{
Mitochondrial reactive oxygen species in cell death signaling
}

Christophe Fleury, Bernard Mignotte, Jean-Luc Vayssière

\section{To cite this version:}

Christophe Fleury, Bernard Mignotte, Jean-Luc Vayssière. Mitochondrial reactive oxygen species in cell death signaling. Biochimie, 2002. hal-03034610

\section{HAL Id: hal-03034610 https://hal.science/hal-03034610}

Submitted on 18 Dec 2020

HAL is a multi-disciplinary open access archive for the deposit and dissemination of scientific research documents, whether they are published or not. The documents may come from teaching and research institutions in France or abroad, or from public or private research centers.
L'archive ouverte pluridisciplinaire HAL, est destinée au dépôt et à la diffusion de documents scientifiques de niveau recherche, publiés ou non, émanant des établissements d'enseignement et de recherche français ou étrangers, des laboratoires publics ou privés. 


\section{Mitochondrial reactive oxygen species in cell death signaling Christophe Fleury, Bernard Mignotte* and Jean-Luc Vayssière}

CNRS - UPRES-A 8087 et Laboratoire de Génétique Moléculaire et Physiologique de l'EPHE, Université de Versailles/Saint-Quentin, Bâtiment Fermat, 45 avenue des Etats-Unis, 78035 VERSAILLES cedex

tel : 0139253650

fax : 0139263655

e mail : mignotte@genetique.uvsq.fr

Abstract - During apoptosis, mitochondrial membranes permeability (MMP) increases and the release into the cytosol of pro-apoptotic factors (procaspases, caspase activators and caspase independent factors as AIF) leads to the apoptotic phenotype. Apart from this pivotal role of mitochondria during the execution phase of apoptosis (documented in other reviews of this issue), it appears that reactive oxygen species (ROS) produced by the mitochondria can be involved in cell death. These toxic compounds are normally detoxified by the cells, failing which oxidative stress occurs.

However, ROS are not only dangerous molecules for the cell, but they also display a physiological role, as mediators in signal transduction pathways. ROS participate in early and late steps of the regulation of apoptosis, according to different possible molecular mechanisms. In agreement with this role of ROS in apoptosis signaling, inhibition of apoptosis by antiapoptotic Bcl2 and $\mathrm{Bcl}-\mathrm{x}_{\mathrm{L}}$ is associated with a protection against ROS and/or a shift of the cellular redox potential to a more reduced state. Furthermore, the fact that active forms of cell death in yeast and plants also involve ROS suggest the existence of an ancestral redox-sensitive death signaling pathway that have been independent of caspases and Bcl-2.

Key words: mitochondria; reactive oxygen species; apoptosis; signaling 


\section{Introduction}

The Bcl-2/Ced-9 family proteins are involved in positive and negative regulation of apoptotic cell death (review in [1]). Among the anti-apoptotic members, Bcl-2 and Bcl- $\mathrm{x}_{\mathrm{L}}$ are negative regulators of cell death, preventing cells from undergoing apoptosis induced by various stimuli in a wide variety of cell types [2,3], whereas others, such as Bax and Bid promote or accelerate cell death. In mammals, most of our understanding of Bcl-2 regulation of apoptosis involves its mitochondrial membrane association. Although for a long time apoptosis was considered to be under the control of nuclear events, mitochondria appear today as the central control point of programmed cell death [4-7]. It is now clear that mitochondrial membraneassociated Bcl-2 acts by regulating the release in the cytosol of pro-apoptotic factors usually sequestered in the mitochondrial intermembrane space (reviewed in other articles of this special issue of "Biochimie"). Moreover, inhibition of apoptosis by antiapoptotic Bcl-2 and Bcl- $\mathrm{x}_{\mathrm{L}}$ is associated with a protection against oxidants and/or a shift of the cellular redox potential to a more reduced state. These results have suggested that reactive oxygen species (ROS) could be mediators of apoptosis. However, others data have shown that apoptosis can occur in very low oxygen environments $[8,9]$, which has cast doubt on this interpretation. A growing number of data show now that ROS, mainly produced by the mitochondria, can be involved in cell death. On the one hand, they can produce an oxidative stress leading to cell destruction, as observed during necrosis or the so-called "post-mitochondrial" phase of apoptosis. On the other hand, in several instances, ROS derived from mitochondria are also involved in the initiation phase of apoptosis contributing to cell death signaling. The present review will focus on the role of mitochondrial ROS in cell death signaling and the possible molecular mechanisms.

\section{Mitochondria are the major site of ROS production}

ROS, such as superoxide anion, radicals, hydrogen and organic peroxides are generated by all aerobic cells as by-products of a number of metabolite reactions and in response to various stimuli [10]. Mitochondria are believed to be a major site of ROS production, according to an endogenous and continuous physiological process under aerobic conditions (figure 1). However, endoplasmic reticulum and nuclear membranes also contain $\mathrm{e}^{-}$transport chains that can lose $\mathrm{e}^{-}$and generate superoxide radical. Some fatty acid metabolites, such as those derived from arachidonic acid by the lipoxygenase pathway, are also ROS.

The physiological activity of the respiratory chain leads to the production of semi quinones, a potential source of ROS [11]. Indeed, the respiratory chain produces ROS at Complex I (NADH/Ubiquinone oxidoreductase) and Complex III (ubiquinol/cytochrome c oxido-reductase [12-14]. The ubiquinone site in complex III appears as the major site of mitochondrial ROS production: this site catalyzes the conversion of molecular oxygen to superoxide anion radical $\left(\mathrm{O}_{2}{ }^{-}\right)$ by a single electron transfer to molecular oxygen (figure 1). Moreover, the inhibition of the respiratory chain, due to a lack of oxygen or to an inhibitor, such as cyanide or antimycin A, increases the ubisemiquinone free radical level in the normal catalytic mechanism of complex III [14].

In aqueous solutions, $\mathrm{O}_{2}^{-}$is moderately reactive but can generate other potent $\mathrm{ROS}$ such as $\mathrm{H}_{2} \mathrm{O}_{2}$ by dismutation. About 1-5\% of mitochondrial $\mathrm{O}_{2}$ consumption leads to $\mathrm{H}_{2} \mathrm{O}_{2}$ production [15]. A reductive homolytic cleavage of $\mathrm{H}_{2} \mathrm{O}_{2}$ produces the highly oxidative and cytotoxic hydroxyl radical $\left(\mathrm{OH}^{*}\right)$ according a metal-dependent breakdown. This highly reactive radical is assumed to be 
directly responsible for most of the oxidative damages leading to the non-physiological necrosis [16]. Alternatively, mitochondria superoxide may react with nitric oxide to produce peroxynitrite [17], a potent oxidant, which causes irreversible inhibition of mitochondria respiration and damage to mitochondria components (complexes I, II, IV and V, creatine kinase, aconitase, membranes, DNA, SOD...). It induces cell death in several cell types [18-21]. Nitric oxide (NO) can also promote or inhibit apoptosis, according the cell type, the rate of production and the interaction with other intracellular molecules [22].

\section{Oxidative stress}

An excess of ROS in mitochondria causes an oxidative stress, with an enhanced activity of the antioxidant defense system and mitochondrial damage. Several situations, such as dysfunctional complex I [23], chemical poisoning and ischaemia followed by reperfusion, may subject tissues and cells to oxidative stress The main targets of ROS in mitochondria are the protein components of the membranes and the polyunsaturated fatty acids. In membranes, ROS and lipids affect cysteine residues (sulfhydryl groups), causing intramolecular cross-linkings and formation of proteins aggregates. $\mathrm{OH}^{*}$ radicals can initiate lipid peroxidation and generate peroxyl- and alkoxyl radical intermediates. Oxidants increase the release of calcium from mitochondria, thus stimulating calcium-dependent enzymes, such as proteases, nucleases and phospholipases. Because of the absence of mitochondria DNA-protecting proteins, the low efficiency reparation mechanism and the proximity of the respiration chain, mtDNA is a privileged target for ROS [24].

\section{Protection of the cell}

To prevent oxidative damage, mammalian cells have developed a complex antioxidant defense system that includes non-enzymatic antioxidants (e.g. glutathione, thioredoxine) as well as enzymatic activities (e.g. catalase, superoxide dismutase (SOD)) [25].

Mitochondria possess an antioxidant system with the superoxide dismutase (SOD), NADH and a complete glutathione redox system, which is formed of glutathione reductase, reduced glutathione (GSH), and glutathione peroxidase (figure 1). This system allows the reduction of oxidants, such as hydroperoxide. As mitochondria are generally devoid of catalase, the hydroperoxide detoxification mainly relies on GSH peroxidase. Various chemicals are known to induce oxidative stress, either as the result of an enhanced free radical production (e.g. xenobiotics utilizing cytochrome P450 for detoxification) or by impairment of their destruction provoked by glutathione depletion. Indeed, irreversible injury may occur following a depletion of the mitochondrial pool of glutathione [26]. Mitochondrial GSH plays an important role in preserving mitochondria membrane integrity and in assuring the reduced state of the intramitochondrial protein thiol groups. Moreover, although coenzyme Q10 can also act as a pro-oxidant [27], it can prevent ROS accumulation occurring under unfavorable condition [28]. Last, macrophages of uncoupling protein-2 deficient mice generate more ROS [29], which is in agreement with the idea that a mitochondrial mild uncoupling and non-coupled oxidations could safe guard cells from high oxygen level and ROS generation [30].

\section{Physiological role}

Cells possess multiple sites for ROS production and a few mechanisms for their degradation. ROS are also involved in different physiological processes, as mediators in signal transduction pathway, activating proteins such as tyrosine kinase, mitogen-activated protein kinase system or small Ras proteins. Current evidence indicates that different stimuli use ROS as signaling 
messengers to activate transcription factors, such as AP-1 and NF- $\kappa \mathrm{B}$, and induce gene expression [31]. Thus, they are responsible for the inducible expression of genes associated with inflammatory and immune responses. Additionally, ROS may have divergent effects according to the cell type, as they can function as mitotic stimuli [32], cellular senescence inducers [33], inhibitors of druginduced tumor cell death [34] or cell death mediators [35, 36]. The large diversity of their effects on cells suggests that ROS not only cause unspecific changes in macromolecules, but also modify a number of signaling pathways.

The ability of oxidative stress, which is an excessive accumulation of ROS, to provoke necrotic cell death as a result of massive cellular damages associated to lipid peroxidation and alterations of proteins and nucleic acids, is well documented for a long time [37]. When free radicals generation exceeds the cellular capacity to detoxify them, cellular protein and DNA damage may occur, leading to the cell death In this point of view, aerobic cells appear as being under a continual "oxidative siege", their survival depending on a balance between ROS and antioxidants.

The possible implication of ROS as signaling molecules in more physiological deaths such as apoptosis is a more recent concept. First evidence suggesting the involvement of mitochondrial ROS in cell death arose from the study of the TNF- $\alpha$-induced cytotoxicity [38, 39]. The observed inhibition of the mitochondrial respiratory chain was assumed to result in the over production of ROS which would act as mediators of the death signaling pathway [40]. There is now mounting evidence that these compounds may be central in the cell death transduction pathways: 1) the addition of ROS or the depletion of endogenous antioxidants can promote cell death [41-44]; 2) some antioxidants, such as thioredoxine or N-acetylcystein, act as intracellular ROS scavengers, and can inhibit activation of caspases and subsequent steps leading to the apoptotic cell death. In these models, ROS could be considered as major mediators, and not only the source of direct damage to DNA, proteins and lipids [45-49]; 3) increases in intracellular ROS are sometimes associated with PCD [50-55]; 4) MnSOD overexpression restores mitochondrial transmembrane potential [56] and inhibits the cell death caused by an inhibition of the respiratory chain [57]; 5) $\mathrm{Cu} / \mathrm{Zn}$ SOD overexpression delays apoptosis by scavenging of $\mathrm{O}_{2}$ - in neuronal cells deprived of nerve growth factor [47] and prevents early release of cytochrome $\mathrm{c}$ in ischemic brain [58]; 6) mitochondrial phospholipid hydroperoxide glutathione peroxidase overexpression inhibits increase of ROS and apoptosis [59] and 7) although some PCD can occur in very low oxygen environments [8, 9], ROS might be produced in such condition [60]. Thus, ROS could be considered as major mediators, and not only the source of direct damage to DNA, proteins and lipids [61]

\section{ROS participate in early and late steps of the regulation of apoptosis}

Since the discovery of ROS involvement in TNF- $\alpha$-induced killing, their contribution to the activation of the execution machinery was extended to PCD triggered by a wide range of apoptosis inducers [62]. Notably, ROS accumulation preceded mitochondrial membrane alterations, nuclear condensation and other typical apoptotic events. This point can be illustrated by TNF- $\alpha$ induced apoptosis. Indeed, experiments using antioxidants show that ROS act upstream of mitochondrial membrane depolarization [63], Bax relocalization, Cytochrome c release, executing caspases activation and nuclear fragmentation (figure 2). Similarly, an early increase in ROS levels has been found to precede mitochondrial membranes permeabilization, and in some case to be independent of caspases, in various models including apoptosis of Retinitis pigmentosa photoreceptors [41, 54] and 
apoptosis induced by Fas [64], p53 [65], ischaemia [66], DNA alkylation [67] or etoposide (Vayssière et al. unpublished results).

Some data raise the possibility that ROS are also required for the execution of the death program $[68,69]$ This must be cautiously considered inasmuch as, in the majority of these systems, it is difficult to ascertain that the observed ROS accumulation corresponds to a causal effect and is not a side effect of the other changes accompanying the killing process [70]. For example, release of cytochrome c triggers accumulation of ROS and increases the oxidation state of the apoptotic cells. Moreover, in these cases, ROS increase most often arises during the later stage of the death program, i.e. during the destruction phase when the cell is broken down, and may be associated with a necrotic type terminal degradation of the cell. Exogenous sources of ROS such as hydrogen peroxide can induce PCD or necrosis depending upon the dose added [44]. So a burst in ROS, in response to a dramatic perturbation of the physiology of the dying cell, could convert the late PCD steps into necrotic death. Therefore, it appears that at any moment the level of intracellular ROS can determine the fate of the cell: low levels of ROS can induce PCD while accumulation of high levels promotes necrosis or can lead PCD-committed cells toward necrotic-like destruction.

\section{Origin of apoptosis-mediated ROS}

Although fatty acid metabolites, such as those produced from arachidonic acid by the lipoxygenase pathway, may be mediators of apoptosis [71], it was established that both ROS accumulation and programmed cell death process require the presence of a functional mitochondrial respiratory chain in most ROS-dependent cell death systems [40, 51, 63, 72]. Indeed, it was shown that an upstream inhibition, with chemical compounds acting on complex I [39, 51], or an elimination of the electron transfer chain [40, 63, 72], by depletion of the mtDNA, prevent ROS accumulation and consequently protect cells against PCD. Another indirect argument is provided by the scavenger role of mitochondrial glutathione in the regulation of ROS-mediated PCD [73]. The ubiquinone site in complex III appears as the major site of mitochondrial ROS production as this site catalyzes the conversion of molecular oxygen to superoxide anion which can lead to the formation of other potent ROS such as hydrogen peroxide and hydrogen radicals (figure 1). The inhibition of the respiratory chain, due to a lack of oxygen or to an inhibitor, such as cyanide or antimycin $\mathrm{A}$, increases the ubisemiquinone free radical level in the normal catalytic mechanism of complex III [14]. Such a model is supported by the observed potentiation of cell death processes in ROS-dependent PCD when electron flow was inhibited distal to the ubiquinone pool.

\section{Mechanisms of ROS signaling}

The involvement of mitochondrial ROS in some cell death transduction pathways leads to the fundamental questions concerning, on the one hand, the causal event of the increased ROS generation and, on the other hand, the molecular mechanisms underlying the ROS signaling. Two viewpoints must first be considered to address the question of the origin of ROS accumulation, which can indeed result from an increased production or from a reduced scavenging by the cellular detoxifying systems. Much of the available data converge to the hypothesis that ROS increases are the consequence of an impairment of the mitochondrial respiratory chain [39, 50, 51, 60, 70, 74]. In agreement with the above considerations, the observed alterations are distal to the ubiquinone site of the complex III, but the origin of these electron flow disturbances are not clear. The only strong evidence comes from the study of ceramide-induced PCD, in which an increased $\mathrm{H}_{2} \mathrm{O}_{2}$ production 
was linked to mitochondrial $\mathrm{Ca}^{2+}$ homeostasis perturbation as inhibition of the mitochondrial $\mathrm{Ca}^{2+}$ uptake was shown to abolish both ROS accumulation and cell death.

Beside the question of the process of mitochondrial ROS accumulation, arises the problematic concerning the targets of these compounds or more precisely: how can they mediate PCD? Unlike fatty acid metabolites which harbor specific reactivity and are known to mediate particular signals from surface receptors, mitochondrial ROS are characterized by a lack of biological specificity or even an extreme reactivity, as for the hydroxyl radical: these are all features contrary to the requirements of a specific signaling role [62]. In this way, a direct influence of ROS on PCD process would be correlated to a general damaging effect on cellular structures resulting in necrotic cell death, or perhaps to a more limited action on mitochondria, their site of production, which in turn could activate some mitochondria-dependent downstream cascades leading to PCD. Another alternative explanation would be to consider that the major effect of an increased ROS production is the subsequent imbalance of intracellular redox status, i.e. an enhancement of the cellular oxidative tonus, and that in fact the oxidative stress is the central common effector of PCD. Hence, ROS accumulation would only be one way which leads in some PCD to an oxidative status. Anti-Fas/APO-1 antibody or IL-3 withdrawal-induced PCD represent good illustrations of this model $[75,76]$. Indeed, no ROS accumulation can be measured in these two systems and anaerobic cultured cells deprived of IL-3 still undergo PCD [9, 77]. However, an oxidative stress can be shown in these models as a depletion of glutathione (GSH), a non-enzymatic cellular antioxidant, as a result of a rapid and specific efflux of glutathione, an event that takes place at the very beginning of the apoptotic process [75, 76]. Moreover, it has been shown that Bcl-2 can protect cells from PCD by shifting the cellular redox potential to a more reduced state (see below). However, the observation that oxidation of thiols other than glutathione can mediate induction of PCD suggest that the intracellular thiol redox status would be the real key factor of the cell death signaling pathways $[42,43,78,79]$. In this model, the redox state of glutathione or other cellular antioxidants such as thioredoxine, would be in equilibrium with that of thiols resident in some redox sensitive crucial components of the execution machinery [80]. Pro-apoptotic members of the Bcl-2 family might be targets for such a regulatory mechanism. Indeed, in healthy cells these proteins are cytosolic, whereas upon a death they redistribute to mitochondria, promoting cell death [81, 82]. One could imagine that such a conformational change is induced by ROS. It has also recently been proposed that ROS could be responsible for a decrease in bcl-xL mRNA levels [55].

Where do ROS fit this thiol hypothesis? In this putative model, an increased production of mitochondrial ROS would result, either by a direct modification of the thiols or indirectly via a depletion of the intracellular antioxidant pool, in a shift of the redox state of the sensor SH groups to a more oxidized state. The nature of the ROS and the level of the intracellular antioxidant defenses would determine in which way regulatory components are activated to commit cells to PCD. In a hypothetical model, mitochondrial ROS modify the membrane permeability leading to the release of pro-apoptotic factors and/or activate directly executing caspases.

\section{Inhibition of apoptosis by $\mathrm{Bcl}-2$ and $\mathrm{Bcl}-\mathrm{x}_{\mathrm{L}}$ is associated with a protection against ROS and/or a shift of the cellular redox potential to a more reduced state}

Several lines of evidence support the idea that Bcl-2, in addition to its role on the regulation of the permeability of the outer mitochondrial membrane, might act as an antioxidant partner to block a putative ROS-mediated step in the cascade of events required for apoptosis. For example, during 
TNF- $\alpha$ induced apoptosis, which involves ROS signaling [63], Bcl-2, as antioxidants do, prevents ROS accumulation and the subsequent events (mitochondrial membrane depolarization, Bax relocalization, Cytochrome $\mathrm{c}$ release, executing caspases activation and nuclear fragmentation) (compare figure 2 and 3). However, the way by which Bcl-2 protects from ROS remains unclear. In some systems, Bcl-2 (or Bcl- $\mathrm{x}_{\mathrm{L}}$ ) appears to influence the generation of ROS [42, 49], while in other cases it does not affect ROS production but does prevent oxidative damage to cellular constituents [83-85]. It has also been proposed that it functions as a pro-oxidant and influences the levels of ROS, inducing in this way endogenous cellular antioxidants [86]. However, bcl-2 knock-out in mice genders perturbation of oxidant metabolism and antioxidant status in some tissues [87].

Since apoptosis might be modulated by redox sensitive proteins, the effect of Bcl-2s on cellular redox potential has been studied. Activities of antioxidant enzymes and levels of glutathione and pyridine nucleotides have been measured in pheochromocytoma PC12 and the hypothalamic GnRH cell line GT1-7 cells transfected with bcl-2 [88] Both cell lines overexpressing bcl-2 had increased total glutathione levels and reduced ratios of oxidized glutathione to total glutathione. In addition, the NAD+/NADH ratio was two- to threefold less than that of control cell lines while they had approximately the same level of catalase, superoxide dismutase, glutathione peroxidase and glutathione reductase activities as control cells. These results indicate that the overexpression of $b c l-2$ shifts the cellular redox potential to a more reduced state, without consistently affecting the major cellular antioxidant enzymes. Furthermore, depleting cellular thiols reversed the resistance to radiation in Bcl-2 expressing lymphoma cell lines [78].

In the same way Bax and Bcl- $x_{L}$ were shown respectively to increase and decrease GSH levels [76] without modifying the activities of superoxide dismutase, catalase, and glutathione peroxidase or glutathione reductase. These results suggest a possible role for GSH in the mechanism by which Bax and Bcl- $x_{\mathrm{L}}$ control cell death.

Thus, both Bcl-2 and Bcl- $x_{L}$ can protect cells from apoptosis by shifting the cellular redox potential to a more reduced state. Assuming that mitochondrial thiols constitute a critical sensor of the cellular redox potential during apoptosis [79], these effects could be at the mitochondrial level.

\section{ROS, plants PCD and Yeast pseudo-apoptosis}

In plants, ROS are also involved in some PCD pathways, such as the synchronous programmed death of petal cells [89], the hypersensitive response (HR) of plants resistant to microbial pathogens [90], or the hormonally regulated cell death pathway in barley aleurone cells [91]. More surprising is the occurrence of a ROS associated apoptosis-like process in unicellular eukaryotic cells like yeasts [92]. Saccharomyces cerevisiae and Schizosaccharomyces pombe yeast species do not contain endogenous caspases or Bcl-2s gene [93-95] and their cytochrome c has been shown to be ineffective to induce nuclear apoptosis in acellular assay [96]. However, several data obtained with $S$. cerevisiae suggest the existence of yet unknown PCD pathways, independent of $\mathrm{Bcl}-2 \mathrm{~s}$ and caspases families, in which the place and the role of mitochondria are not fully understood. The $\mathrm{cdc} 48^{\mathrm{S} 565 \mathrm{G}}$ mutant show typical markers of apoptosis, including exposure of phosphatidylserine, chromatin condensation and fragmentation, DNA fragmentation, and formation of minicells, which look like apoptotic bodies and it has been recently observed some markers of oxidative stress and apoptosis in aged mother cells of S. cerevisiae [97]. The heterologous expression of mammalian pro-apoptotic genes (ced-4, bax, bak) provokes mitochondrial dysfunction and the death of $S$. cerevisiae and $S$. pombe cells [93, 95, 98-101]. Several authors reported that this induced-cytotoxicity was characterized by typical phenotypic markers of 
apoptosis [95, 101], identical to those observed in the pseudo-apoptotic mutant $\operatorname{cdc} 48^{\mathrm{S} 565 \mathrm{G}}$ [92], and other features, such as release of cytochrome c [102]. Moreover, as observed in mammals, coexpression of Bcl-2 or Bcl- $\mathrm{x}_{\mathrm{L}}$ with Bax abolishes the pseudo-apoptotic phenotype and the cell death [101-106]. Since on the one hand, Bax cytotoxicity is increased under respiratory condition [107], and, on the other hand, yeast mutants lacking superoxide dismutase were partially rescued by expression of Bcl-2 [42, 108], it is tempting to speculate that a mitochondrial ROS production is involved in the pseudo-apoptotic process. In agreement with this hypothesis, the apoptotic-like features observed in these yeast strains are accompanied with ROS accumulation [109]. Moreover, low concentration of $\mathrm{H}_{2} \mathrm{O}_{2}$ treatment or glutathione depletion could induce the pseudo-apoptosis in yeast [109]. The induced-cell death is not due to a direct cell damage, but requires an active cooperation of the cell machinery. In all these models, ROS accumulation seems to be necessary and sufficient to lead to the pseudo-apoptotic phenotype. These observations suggest the existence, in yeasts, of an ancestral redox-sensitive apoptosis pathway, which is independent of caspases and Bcl-2.

\section{Conclusion}

In conclusion, mitochondria are involved in the decision of cells to survive or not at several levels (figure 4). First, mitochondria can activate the cell death machinery by releasing in the cytosol pro-apoptotic factors such as procaspases, caspase activators (i.e. cytochrome c and Smac/Diablo) or caspase independent factors as AIF. Furthermore, the importance of mitochondria in apoptosis has been reinforced by studies showing the contribution of reactive oxygen species in the cell-death signaling. The mechanism of ROS signaling is still unknown, but it could be speculated that they act by modifying the activity of some apoptotic key regulators, such as proteins of the Bcl-2 family. If the primer function of apoptosis was possibly to clear ROS-producing cells from tissues [110, 111], mitochondrial ROS production are used as active mediators in the regulation of apoptosis at different levels. Moreover, the fact that pseudo-apoptosis phenotype in yeast invariably involves ROS [109] points out these compounds as major evolution-conserved regulators of cell death.

\section{References}

1 Gross, A., McDonnell, J.M. and Korsmeyer, S.J., BCL-2 family members and the mitochondria in apoptosis, Genes Dev. 13, (1999) 1899-1911.

2 Korsmeyer, S.J., Bcl-2 initiates a new category of oncogenes: regulators of cell death, Blood 80, (1992) 879-886.

3 Zhong, L.T., Sarafian, T., Kane, D.J., Charles, A.C., Mah, S.P., Edwards, R.H. and Bredesen, D.E., $b c l-2$ inhibits death of central neural cells induced by multiple agents, Proc. Natl. Acad. Sci. USA 90, (1993) 4533-4537.

4 Mignotte, B. and Vayssière, J.L., Mitochondria and apoptosis, Eur. J. Biochem. 252, (1998) $1-15$.

5 Desagher, S. and Martinou, J.C., Mitochondria as the central control point of apoptosis, Trends Cell Biol. 10, (2000) 369-377.

6 Zamzami, N. and Kroemer, G., The mitochondrion in apoptosis: how Pandora's box opens, Nat. Rev. Mol. Cell Biol. 2, (2001) 67-71.

7 Ferri, K.F. and Kroemer, G., Mitochondria: the suicide organelles, Bioessays 23, (2001) 111-115. 
8 Jacobson, M.D. and Raff, M.C., Programmed cell death and Bcl-2 protection in very low oxygen, Nature 374, (1995) 814-816.

9 Shimizu, S., Eguchi, Y., Kosaka, H., Kamiike, W., Matsuda, H. and Tsujimoto, Y., Prevention of hypoxia-induced cell death by Bcl-2 and Bcl-X $\mathrm{L}_{\mathrm{L}}$, Nature 374, (1995) 811-813.

10 Fridovich, I., The biology of oxygen radicals, Science 201, (1978) 875-880.

11 Papa, S. and Skulachev, V.P., Reactive oxygen species, mitochondria, apoptosis and aging, Mol Cell Biochem 174, (1997) 305-319.

12 Takeshige, K. and Minakami, S., NADH- and NADPH-dependent formation of superoxide anions by bovine heart submitochondrial particles and NADH-ubiquinone reductase preparation, Biochem J 180, (1979) 129-135.

13 Boveris, A., Cadenas, E. and Stoppani, A.O., Role of ubiquinone in the mitochondrial generation of hydrogen peroxide, Biochem J 156, (1976) 435-444.

14 Turrens, J.F., Alexandre, A. and Lehninger, A.L., Ubisemiquinone is the electron donor for superoxide formation by complex III of heart mitochondria, Arch. Biochem. Biophys. 237, (1985) 408-414.

15 Chance, B., Sies, H. and Boveris, A., Hydroperoxide metabolism in mammalian organs, Physiol Rev 59, (1979) 527-605.

16 Halliwell, B. and Gutteridge, J.M., Role of free radicals and catalytic metal ions in human disease: an overview, Methods Enzymol. , (1990) 1-85.

17 Groves, J.T., Peroxynitrite: reactive, invasive and enigmatic, Curr Opin Chem Biol 3, (1999) 226-35.

18 Szabo, C. and Ohshima, H., DNA damage induced by peroxynitrite: subsequent biological effects, Nitric Oxide 1, (1997) 373-385.

19 O'Connor, M., Salzman, A.L. and Szabo, C., Role of peroxynitrite in the protein oxidation and apoptotic DNA fragmentation in vascular smooth muscle cells stimulated with bacterial lipopolysaccharide and interferon-gamma, Shock 8, (1997) 439-443.

20 Lin, K.T., Xue, J.Y., Lin, M.C., Spokas, E.G., Sun, F.F. and Wong, P.Y., Peroxynitrite induces apoptosis of HL-60 cells by activation of a caspase-3 family protease, Am J Physiol 274, (1998) C855-60.

21 Liu, G.Y., Chen, K.J., Lin-Shiau, S.Y. and Lin, J.K., Peroxyacetyl nitrate-induced apoptosis through generation of reactive oxygen species in HL-60 cells, Mol Carcinog 25, (1999) 196206.

22 Chung, H.T., Pae, H.O., Choi, B.M., Billiar, T.R. and Kim, Y.M., Nitric oxide as a bioregulator of apoptosis, Biochem Biophys Res Commun 282, (2001) 1075-9.

23 Robinson, B.H., Human complex I deficiency: clinical spectrum and involvement of oxygen free radicals in the pathogenicity of the defect, Biochim Biophys Acta 1364, (1998) 271286.

24 Shoji, Y., Uedono, Y., Ishikura, H., Takeyama, N. and Tanaka, T., DNA damage induced by tumour necrosis factor-alpha in L929 cells is mediated by mitochondrial oxygen radical formation, Immunology 84, (1995) 543-548.

25 Sies, H., Oxidative stress: from basic research to clinical application, Am. J. Med. 91, (1991) 31S-38S.

26 Reed, D.J., Glutathione: toxicological implications, Annu Rev Pharmacol Toxicol 30, (1990) 603-31. 
27 Yamamura, T., Otani, H., Nakao, Y., Hattori, R., Osako, M., Imamura, H. and Das, D.K., Dual involvement of coenzyme Q10 in redox signaling and inhibition of death signaling in the rat heart mitochondria, Antioxid Redox Signal 3, (2001) 103-12.

28 Teranishi, M., Karbowski, M., Kurono, C., Nishizawa, Y., Usukura, J., Soji, T. and Wakabayashi, T., Effects of coenzyme Q10 on changes in the membrane potential and rate of generation of reactive oxygen species in hydrazine- and chloramphenicol-treated rat liver mitochondria, Arch Biochem Biophys 366, (1999) 157-167.

29 Arsenijevic, D., Onuma, H., Pecqueur, C., Raimbault, S., Manning, B.S., Miroux, B., Couplan, E., Alves-Guerra, M.C., Goubern, M., Surwit, R., Bouillaud, F., Richard, D., Collins, S. and Ricquier, D., Disruption of the uncoupling protein-2 gene in mice reveals a role in immunity and reactive oxygen species production, Nat Genet 26, (2000) 435-9.

30 Skulachev, V.P., Uncoupling: new approaches to an old problem of bioenergetics, Biochim. Biophys. Acta 1363, (1998) 100-124.

31 Pinkus, R., Weiner, L.M. and Daniel, V., Role of Oxidants and Antioxidants in the Induction of AP-1, NF-kB, and Glutathione S-Transferase Gene Expression., J. Biol. Chem. 271, (1996) 13422-13429.

32 Clement, M.V. and Pervaiz, S., Reactive oxygen intermediates regulate cellular response to apoptotic stimuli: an hypothesis, Free Radic Res 30, (1999) 247-252.

33 Lundberg, A.S., Hahn, W.C., Gupta, P. and Weinberg, R.A., Genes involved in senescence and immortalization, Curr Opin Cell Biol 12, (2000) 705-9.

34 Pervaiz, S., Ramalingam , J.K., Hirpara , J.L. and Clement, M., Superoxide anion inhibits drug-induced tumor cell death, FEBS Letters , (1999) in press.

35 Burdon, R.H., Control of cell proliferation by reactive oxygen species, Biochem Soc Trans 24, (1996) 1028-1032.

36 Burdon, R.H., Superoxide and hydrogen peroxide in relation to mammalian cell proliferation, Free Radic Biol Med 18, (1995) 775-794.

37 Halliwell, B. and Gutteridge, J.M.C. Free radicals in Biology and Medecine (1989), Second edition ed., Clarendon Press, Oxford, London.

38 Lancaster, J.R., Laster, S.M. and Gooding, L.R., Inhibition of target cell mitochondrial electron transfer by tumor necrosis factor, FEBS Lett. 248, (1989) 169-174.

39 Schulze-Osthoff, K., Bakker, A.C., Vanhaesebroeck, B., Beyaert, R., Jacob, W.A. and Fiers, W., Cytotoxic activity of tumor necrosis factor is mediated by early damage of mitochondrial functions. Evidence for the involvement of mitochondrial radical generation, J. Biol. Chem. 267, (1992) 5317-5323.

40 Schulze-Osthoff, K., Beyaert, R., Vandevoorde, V., Haegeman, G. and Fiers, W., Depletion of the mitochondrial electron transport abrogates the cytotoxic and Gene-Inductive effects of TNF, EMBO J. 12, (1993) 3095-3104.

41 Carmody, R.J., McGowan, A.J. and Cotter, T.G., Reactive oxygen species as mediators of photoreceptor apoptosis in vitro, Exp Cell Res 248, (1999) 520-530.

42 Kane, D.J., Sarafian, T.A., Anton, R., Hahn, H., Gralla, E.B., Valentine, J.S., Ord, T. and Bredesen, D.E., Bcl-2 inhibition of neural death - decreased generation of reactive oxygen species, Science 262, (1993) 1274-1277.

43 Sato, N., Iwata, S., Nakamura, K., Hori, T., Mori, K. and Yodoi, J., Thiol-Mediated Redox Regulation of Apoptosis. Possible roles of cellular thiols other than glutathione in $\mathrm{T}$ cell apoptosis, J. Immunol. 154, (1995) 3194-3203. 
44 Guénal, I., Sidoti-de Fraisse, C., Gaumer, S. and Mignotte, B., Bcl-2 and Hsp27 act at different levels to suppress programmed cell death, Oncogene 15, (1997) 347-360.

45 Iwata, S., Hori, T., Sato, N., Hirota, K., Sasada, T., Mitsui, A., Hirakawa, T. and Yodoi, J., Adult $\mathrm{T}$ cell leukemia (ATL)-derived factor/human thioredoxin prevents apoptosis of lymphoid cells induced by L-cystine and glutathione depletion: possible involvement of thiol-mediated redox regulation in apoptosis caused by pro-oxidant state, J Immunol 158, (1997) 3108-3117.

46 Mayer, M. and Noble, M., N-acetyl-L-cysteine is a pluripotent protector against cell death and enhancer of trophic factor-mediated cell survival in vitro, Proc. Natl. Acad. Sci. USA 91, (1994) 7496-7500.

47 Greenlund, L.J.S., Deckwerth, T.L. and Johnson Jr, E.M., Superoxide dismutase delays neuronal apoptosis: a role for reactive oxygen species in programmed neuronal death, Neuron 14, (1995) 303-315.

48 Mehlen, P., Schulze-Osthoff, K. and Arrigo, A.P., Small stress proteins as novel regulators of apoptosis, J. Biol. Chem. 271, (1996) 16510-16514.

49 Gottlieb, E., Vander Heiden, M.G. and Thompson, C.B., Bcl-x(L) prevents the initial decrease in mitochondrial membrane potential and subsequent reactive oxygen species production during tumor necrosis factor alpha-induced apoptosis, Mol. Cell. Biol. 20, (2000) 5680-5689.

50 France-Lanord, V., Brugg, B., Michel, P.P., Agid, Y. and Ruberg, M., Mitochondrial free radical signal in ceramide-dependent apoptosis: a putative mechanism for neuronal death in Parkinson's disease, J Neurochem 69, (1997) 1612-1621.

51 Quillet-Mary, A., Jaffrezou, J.P., Mansat, V., Bordier, C., Naval, J. and Laurent, G., Implication of mitochondrial hydrogen peroxide generation in ceramide- induced apoptosis, J. Biol. Chem. 272, (1997) 21388-21395.

52 Li, P.F., Dietz, R. and von Harsdorf, R., Superoxide induces apoptosis in cardiomyocytes, but proliferation and expression of transforming growth factor-beta1 in cardiac fibroblasts, FEBS Lett 448, (1999) 206-210.

53 Manna, S.K., Zhang, H.J., Yan, T., Oberley, L.W. and Aggarwal, B.B., Overexpression of manganese superoxide dismutase suppresses tumor necrosis factor-induced apoptosis and activation of nuclear transcription factor-kappaB and activated protein-1, J Biol Chem 273, (1998) 13245-13254.

54 Carmody, R.J. and Cotter, T.G., Oxidative stress induces caspase-independent retinal apoptosis in vitro, Cell Death Differ 7, (2000) 282-91.

55 Herrera, B., Alvarez, A.M., Sanchez, A., Fernandez, M., Roncero, C., Benito, M. and Fabregat, I., Reactive oxygen species (ROS) mediates the mitochondrial-dependent apoptosis induced by transforming growth factor (beta) in fetal hepatocytes, Faseb J 15, (2001) 741-51.

56 Majima, H.J., Oberley, T.D., Furukawa, K., Mattson, M.P., Yen, H.C., Szweda, L.I. and St, C.D., Prevention of mitochondrial injury by manganese superoxide dismutase reveals a primary mechanism for alkaline-induced cell death, J. Biol. Chem. 273, (1998) 8217-8224.

57 Kiningham, K.K., Oberley, T.D., Lin, S., Mattingly, C.A. and St Clair, D.K., Overexpression of manganese superoxide dismutase protects against mitochondrial-initiated poly(ADP-ribose) polymerase-mediated cell death, Faseb J 13, (1999) 1601-1610. 
Fujimura, M., Morita-Fujimura, Y., Noshita, N., Sugawara, T., Kawase, M. and Chan, P.H., The cytosolic antioxidant copper/zinc-superoxide dismutase prevents the early release of mitochondrial cytochrome $\mathrm{c}$ in ischemic brain after transient focal cerebral ischemia in mice, J Neurosci 20, (2000) 2817-24.

59 Nomura, K., Imai, H., Koumura, T., Arai, M. and Nakagawa, Y., Mitochondrial Phospholipid Hydroperoxide Glutathione Peroxidase Suppresses Apoptosis Mediated by a Mitochondrial Death Pathway, J Biol Chem 274, (1999) 29294-29302.

60 Degli Esposti, M. and McLennan, H., Mitochondria and cells produce reactive oxygen species in virtual anaerobiosis: relevance to ceramide-induced apoptosis, FEBS Lett. 430, (1998) 338-342.

61 Tan, S., Sagara, Y., Liu, Y., Maher, P. and Schubert, D., The regulation of reactive oxygen species production during programmed cell death, J Cell Biol 141, (1998) 1423-1432.

62 Jacobson, M.D., Reactive oxygen species and programmed cell death, Trends Biochem. Sci. 21, (1996) 83-86.

63 Sidoti-de Fraisse, C., Rincheval, V., Risler, Y., Mignotte, B. and Vayssière, J.L., TNF- $\alpha$ activates at least two apoptotic signaling cascades, Oncogene 17, (1998) 1639-1651.

64 Banki, K., Hutter, E., Gonchoroff, N.J. and Perl, A., Elevation of mitochondrial transmembrane potential and reactive oxygen intermediate levels are early events and occur independently from activation of caspases in Fas signaling, J Immunol 162, (1999) 14661479.

65 Li, P.F., Dietz, R. and von Harsdorf, R., p53 regulates mitochondrial membrane potential through reactive oxygen species and induces cytochrome c-independent apoptosis blocked by Bcl-2, EMBO J. 18, (1999) 6027-6036.

66 Maulik, N., Yoshida, T. and Das, D.K., Oxidative stress developed during the reperfusion of ischemic myocardium induces apoptosis, Free Radic Biol Med 24, (1998) 869-875.

67 Tada-Oikawa, S., Oikawa, S., Kawanishi, M., Yamada, M. and Kawanishi, S., Generation of hydrogen peroxide precedes loss of mitochondrial membrane potential during DNA alkylation-induced apoptosis, FEBS Lett 442, (1999) 65-69.

68 Kroemer, G., Petit, P.X., Zamzami, N., Vayssière, J.L. and Mignotte, B., The biochemistry of programmed cell death, FASEB J. 9, (1995) 1277-1287.

69 Schulz, J.B., Weller, M. and Klockgether, T., Potassium deprivation-induced apoptosis of cerebellar granule neurons: a sequential requirement for new mRNA and protein synthesis, ICE-like protease activity, and reactive oxygen species, J Neurosci 16, (1996) 4696-4706.

70 Cai, J. and Jones, D.P., Superoxide in apoptosis. Mitochondrial generation triggered by cytochrome c loss, J. Biol. Chem. 273, (1998) 11401-11404.

71 O'Donnell, V.B., Spycher, S. and Azzi, A., Involvement of oxidants and oxidant-generating enzyme(s) in tumour- necrosis-factor-alpha-mediated apoptosis: role for lipoxygenase pathway but not mitochondrial respiratory chain, Biochem J 310, (1995) 133-141.

72 Higuchi, M., Aggarwal, B.B. and Yeh, E.T., Activation of CPP32-like protease in tumor necrosis factor-induced apoptosis is dependent on mitochondrial function, J. Clin. Invest. 99, (1997) 1751-1758.

73 Goossens, V., Grooten, J., De, V.K. and Fiers, W., Direct evidence for tumor necrosis factor-induced mitochondrial reactive oxygen intermediates and their involvement in cytotoxicity, Proc. Natl. Acad. Sci. USA 92, (1995) 8115-8119. 
74 Gudz, T.I., Tserng, K.Y. and Hoppel, C.L., Direct inhibition of mitochondrial respiratory cahin complex III by cell-permeable ceramide, J. Biol. Chem. 272, (1997) 24154-24158. van den Dobbelsteen, D.J., Nobel, C.S.I., Schlegel, J., Cotgreave, I.A., Orrenius, S. and Slater, A.F.G., Rapid and Specific Efflux of Reduced Glutathione during Apoptosis Induced by Anti-Fas/APO-1 Antibody, J. Biol. Chem. 271, (1996) 15420-15427.

76 Bojes, H.K., Datta, K., Xu, J., Chin, A., Simonian, P., Nunez, G. and Kehrer, J.P., Bcl-XL overexpression attenuates glutathione depletion in FL5.12 cells following interleukin-3 withdrawal, Biochem. J. 325, (1997) 315-319.

77 Schulze-Osthoff, K., Krammer, P.H. and Droge, W., Divergent signalling via APO-1/Fas and the TNF receptor, two homologous molecules involved in physiological cell death, EMBO J. 13, (1994) 4587-4596.

78 Mirkovic, N., Voehringer, D.W., Story, M.D., McConkey, D.J., McDonnell, T.J. and Meyn, R.E., Resistance to radiation-induced apoptosis in Bcl-2-expressing cells is reversed by depleting cellular thiols, Oncogene 15, (1997) 1461-1470.

79 Marchetti, P., Decaudin, D., Macho, A., Zamzami, N., Hirsch, T., Susin, S.A. and Kroemer, G., Redox regulation of apoptosis: impact of thiol oxidation status on mitochondrial function, Eur. J. Immunol. 27, (1997) 289-296.

80 Kroemer, G., Zamzami, N. and Susin, S.A., Mitochondrial control of apoptosis, Immunol. Today 18, (1997) 44-51.

81 Wolter, K.G., Hsu, Y.T., Smith, C.L., Nechushtan, A., Xi, X.G. and Youle, R.J., Movement of Bax from the Cytosol to Mitochondria during Apoptosis, J. Cell. Biol. 139, (1997) 12811292.

82 Hsu, Y.T. and Youle, R.J., Bax in murine thymus is a soluble monomeric protein that displays differential detergent-induced conformations, J. Biol. Chem. 273, (1998) 1077710783.

83 Hockenbery, D.M., Oltvai, Z.N., Yin, X.M., Milliman, C.L. and Korsmeyer, S.J., Bcl-2 functions in an antioxidant pathway to prevent apoptosis, Cell 75, (1993) 241-251.

84 Tyurina, Y.Y., Tyurin, V.A., Carta, G., Quinn, P.J., Schor, N.F. and Kagan, V.E., Direct evidence for antioxidant effect of Bcl-2 in PC12 rat pheochromocytoma cells, Arch. Biochem. Biophys. 344, (1997) 413-423.

85 Satoh, T., Enokido, Y., Aoshima, H., Uchiyama, Y. and Hatanaka, H., Changes in mitochondrial membrane potential during oxidative stress- induced apoptosis in PC12 cells, J Neurosci Res 50, (1997) 413-420.

86 Steinman, H.M., The Bcl-2 oncoprotein functions as a pro-oxidant, J. Biol. Chem. 270, (1995) 3487-3490.

87 Hochman, A., Liang, H., Offen, D., Melamed, E. and Sternin, H., Developmental changes in antioxidant enzymes and oxidative damage in kidneys, liver and brain of bcl-2 knockout mice, Cell Mol Biol (Noisy-le-grand) 46, (2000) 41-52.

88 Ellerby, L.M., Ellerby, H.M., Park, S.M., Holleran, A.L., Murphy, A.N., Fiskum, G., Kane, D.J., Testa, M.P., Kayalar, C. and Bredesen, D.E., Shift of the cellular oxidation-reduction potential in neural cells expressing Bcl-2, J. Neurochem. 67, (1996) 1259-1267.

89 Rubinstein, B., Regulation of cell death in flower petals, Plant Mol Biol 44, (2000) 303-18.

90 Heath, M.C., Hypersensitive response-related death, Plant Mol Biol 44, (2000) 321-34.

91 Bethke, P.C. and Jones, R.L., Cell death of barley aleurone protoplasts is mediated by reactive oxygen species, Plant J 25, (2001) 19-29. 
92 Madeo, F., Frohlich, E. and Frohlich, K.U., A yeast mutant showing diagnostic markers of early and late apoptosis, J. Cell Biol. 139, (1997) 729-734.

93 Greenhalf, W., Stephan, C. and Chaudhuri, B., Role of mitochondria and C-terminal membrane anchor Bcl-2 in Bax induced growth arrest and mortality in Saccharomyces cerevisiae, FEBS lett. 380, (1996) 169-175.

94 Zha, H., Fisk, H.A., Yaffe, M.P., Mahajan, N., Herman, B. and Reed, J.C., Structurefunction comparisons of the proapoptotic protein Bax in yeast and mammalian cells, Mol. Cell. Biol. 16, (1996) 6494-6508.

95 Ink, B., Zornig, M., Baum, B., Hajibagheri, N., James, C., Chittenden, T. and Evan, G., Human Bak induces cell death in Schizosaccharomyces pombe with morphological changes similar to those with apoptosis in mammalian cells, Mol. Cell. Biol. 17, (1997) 2468-2474.

96 Kluck, R.M., Martin, S.J., Hoffman, B., Zhou, J.S., Green, D.R. and Newmeyer, D.D., Cytochrome c activation of CPP32-like proteolysis plays a critical role in a Xenopus cellfree apoptosis system, EMBO J. 16, (1997) 4639-4649.

97 Laun, P., Pichova, A., Madeo, F., Fuchs, J., Ellinger, A., Kohlwein, S., Dawes, I., Frohlich, K.U. and Breitenbach, M., Aged mother cells of Saccharomyces cerevisiae show markers of oxidative stress and apoptosis, Mol Microbiol 39, (2001) 1166-73.

98 Sato, T., Hanada, M., Bodrug, S., Irie, S., Iwama, N., Boise, L.H., Thompson, C.B., Golemis, E., Fong, L., Wang, H.G. and Reed, J.C., Interactions among members of the Bcl-2 protein family analyzed with a yeast two-hybrid system, Proc. Natl. Acad. Sci. U S A 91, (1994) 9238-9242.

99 Hanada, M., Aime-Sempe, C., Sato, T. and Reed, J.C., Structure-function analysis of Bcl-2 protein. Identification of conserved domains important for homodimerization with Bcl-2 and heterodimerization with Bax, J. Biol. Chem. 270, (1995) 11962-11969.

100 James, C., Gschmeissner, S., Fraser, A. and Evan, G.I., CED-4 induces chromatin condensation in Schizosaccharomyces pombe and is inhibited by direct physical association with CED-9, Curr. Biol. 7, (1997) 246-252.

101 Ligr, M., Madeo, F., Frohlich, E., Hilt, W., Frohlich, K.U. and Wolf, D.H., Mammalian Bax triggers apoptotic changes in yeast, FEBS Lett. 438, (1998) 61-65.

102 Manon, S., Chaudhuri, B. and Guerin, M., Release of cytochrome c and decrease of cytochrome c oxidase in Bax- expressing yeast cells, and prevention of these effects by coexpression of Bcl-xL, FEBS Lett. 415, (1997) 29-32.

103 Zha, H., Aime-Sempe, C., Sato, T. and Reed, J.C., Proapoptotic protein Bax heterodimerizes with Bcl-2 and homodimerizes with Bax via a novel domain (BH3) distinct from BH1 and BH2, J. Biol. Chem. 271, (1996) 7440-7444.

104 Jürgensmeier, J., Krajewski, S., Armstrong, R.C., Wilson, G.M., Olterdorf, T., Fritz, L.C., Reed, J.C. and Ottilie, S., Bax- and Bak-induced cell death in the fission yeast Schizosaccharomyces pombe, Mol. Biol. Cell 8, (1997) 325-339.

105 Tao, W., Kurschner, C. and Morgan, J.I., Modulation of cell death in yeast by the Bcl-2 family of proteins, J. Biol. Chem. 272, (1997) 15547-15552.

106 Matsuyama, S., Xu, Q., Velours, J. and Reed, J.C., The Mitochondrial F0F1-ATPase proton pump is required for function of the proapoptotic protein Bax in yeast and mammalian cells, Mol. Cell 1, (1998) 327-336.

107 Priault, M., Camougrand, N., Chaudhuri, B., Schaeffer, J. and Manon, S., Comparison of the effects of bax-expression in yeast under fermentative and respiratory conditions: 
investigation of the role of adenine nucleotides carrier and cytochrome c, FEBS Lett. 456, (1999) 232-238.

108 Longo, V.D., Ellerby, L.M., Bredesen, D.E., Valentine, J.S. and Gralla, E.B., Human Bcl-2 reverses survival defects in yeast lacking superoxide dismutase and delays death of wildtype yeast, J. Cell Biol. 137, (1997) 1581-1588.

109 Madeo, F., Frohlich, E., Ligr, M., Grey, M., Sigrist, S.J., Wolf, D.H. and Frohlich, K.U., Oxygen stress: a regulator of apoptosis in yeast, J Cell Biol 145, (1999) 757-767.

110 Skulachev, V.P., Why are mitochondria involved in apoptosis? Permeability transition pores and apoptosis as selective mechanisms to eliminate superoxide- producing mitochondria and cell, FEBS Lett 397, (1996) 7-10.

111 Skulachev, V.P., Cytochrome $\mathrm{c}$ in the apoptotic and antioxidant cascades, FEBS Lett. 423, (1998) 275-280.

112 Fleury, C., Mignotte, B. and Vayssière, J.L., Mitochondrial reactive oxygen species and apoptosis, in Mitochondrial Ubiquinone (Coenzyme Q10): Biomedical, Functional, Medical and Therapeutic Aspects in Human Health and Disease (Ebadi, M., Marwah, J. and Chopra, R.K., eds.), Prominent Press, Arizona, (2001) pp. 361-398.

113 Banki, K., Hutter, E., Colombo, E., Gonchoroff, N.J. and Perl, A., Glutathione levels and sensitivity to apoptosis are regulated by changes in transaldolase expression, $\mathrm{J}$ Biol Chem 271, (1996) 32994-33001. 


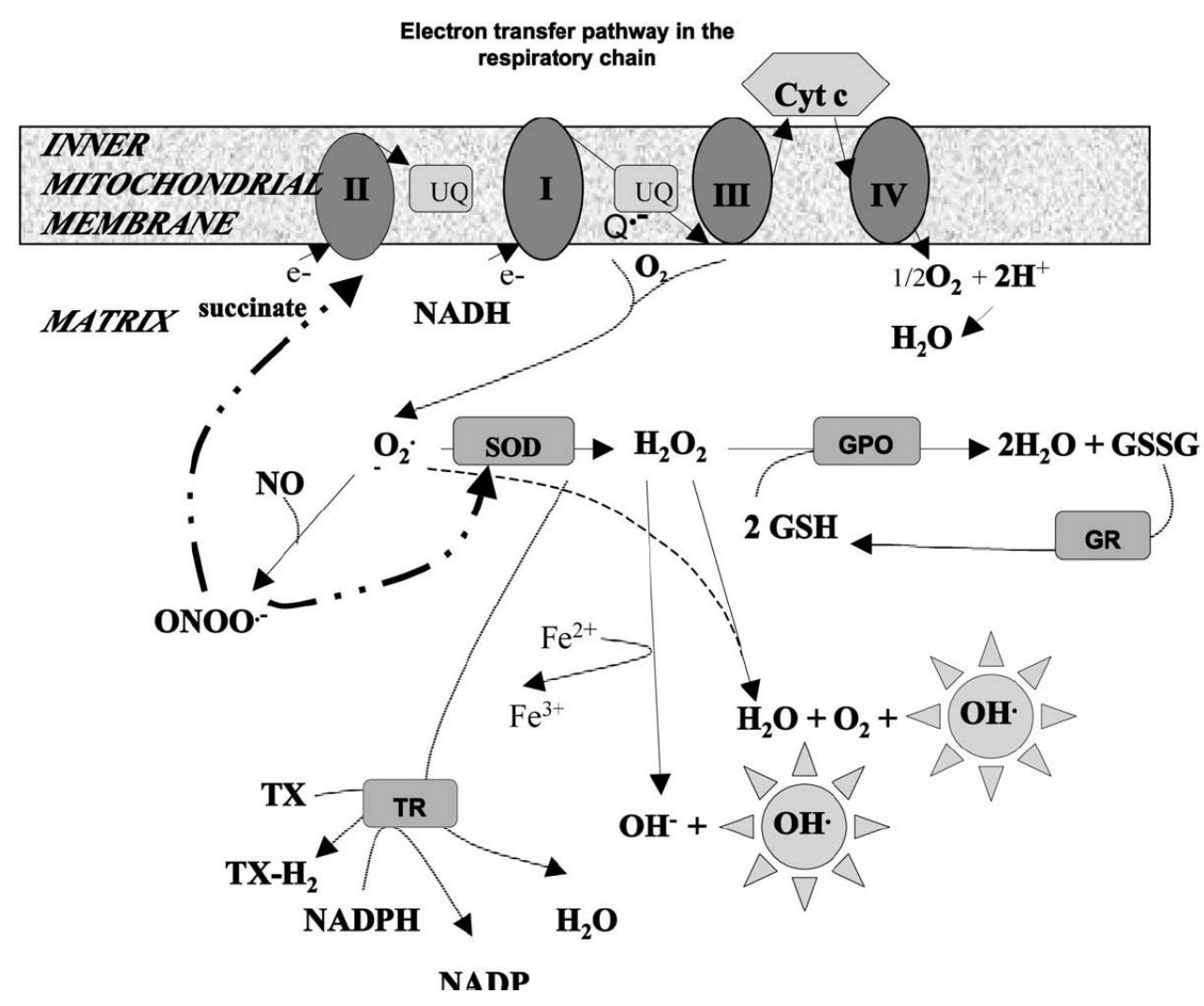

Figure 1: Schematic representation of the formation and the fate of superoxide ions $\left(\mathrm{O}_{2}{ }^{-}\right)$in mitochondria (adapted from Fleury et al. [112]).

ROS can be generated by various enzymes (xanthine oxidase, lipoxygenases, NADPH oxidases,...) or during the mitochondrial oxidative phosphorylation at complex I and complex III (see text). Complex I (NADH-ubiquinone oxidoreductase) catalyzes the following reaction with electron transfer: $\mathrm{NADH}+\mathrm{Q}+\mathrm{nH}^{+}{ }_{\text {(matrix })}<->\mathrm{NAD}^{+}+\mathrm{QH}_{2}+(\mathrm{n}-1) \mathrm{H}^{+}{ }_{\text {(intermembrane space), }}$ where $\mathrm{Q}$ is the ubiquinone Q10. The ubiquinone site (UQ) in complex III catalyzes the conversion of molecular oxygen to superoxide anion radical $\left(\mathrm{O}_{2^{-}}\right)$by a single electron transfer to molecular oxygen. $\mathrm{O}_{2} \cdot-$ are converted to hydrogen peroxide $\left(\mathrm{H}_{2} \mathrm{O}_{2}\right)$ by the superoxide dismutase (SOD).

$\mathrm{H}_{2} \mathrm{O}_{2}$ detoxification normally occurs according two different reactions, either by the thioredoxine reductase (TR), which reduces thioredoxine (TX $\rightarrow \mathrm{TX}-\mathrm{H}_{2}$ ), or by reacting with glutathione (GSH) by glutathione peroxidase (GPO). The latter reaction produces water and oxidized glutathione (GSSG), and GSSG is recycled to GSH by glutathione reductase (GR). Glutathione is mainly maintained in a reduced state, via NADPH generation in the reversible nonoxidative part of the pentose phosphate pathway [113]. When GSH level is low, $\mathrm{H}_{2} \mathrm{O}_{2}$ can react with $\mathrm{Fe}^{2+}$ to produce $\mathrm{OH}^{-}$and the harmful hydroxyl anions $(\mathrm{OH} \cdot)$. Alternatively, $\mathrm{H}_{2} \mathrm{O}_{2}$ reacts with $\mathrm{O}_{2}$.producing water, molecular oxygen and $\mathrm{OH}$.

Superoxide may also react with nitric oxide (NO) to produce peroxynitrite (ONOO**), a potent oxidant, which causes irreversible inhibition of mitochondria respiration and damage to mitochondria components (complexes I, II, IV and V, creatine kinase, aconitase, membranes, DNA, SOD,$\ldots)$.

The complexes of the electron transfer chain in the inner mitochondrial membrane are numbered from I to IV. The electron (e-) pathway through the respiratory chain is indicated by arrows. Cyt c refers to cytochrome c. 


\section{HeLa+TNF}

HeLa+TNF
HEVD

$+D E V D$

\section{HeLa+TNF \\ + BHA}
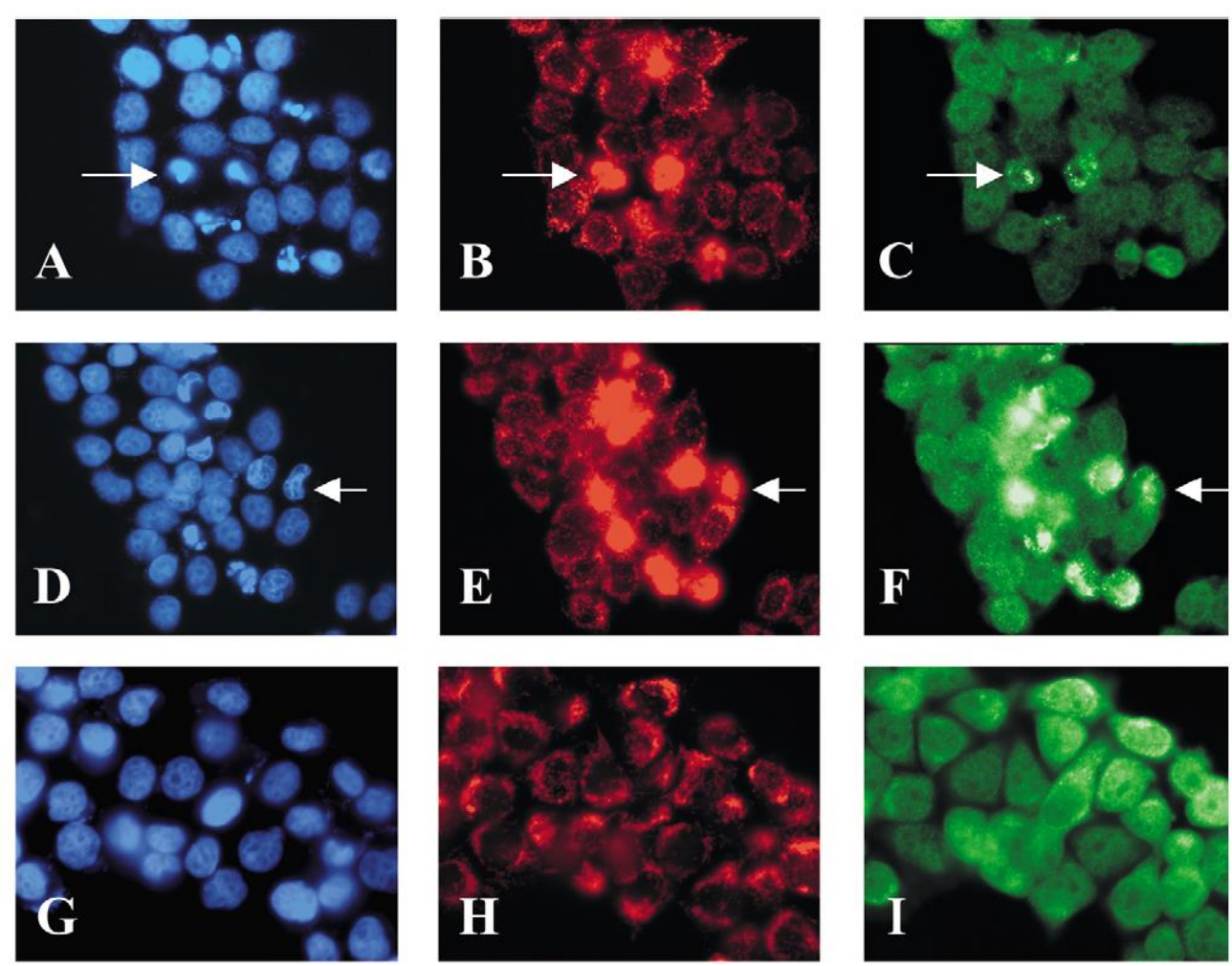

Hoechst

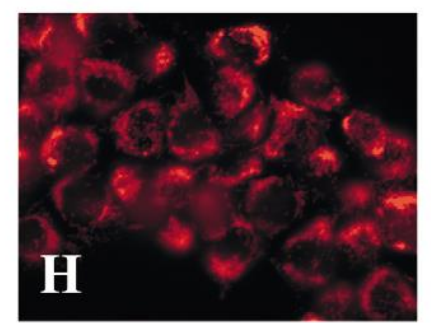

cytochrome c

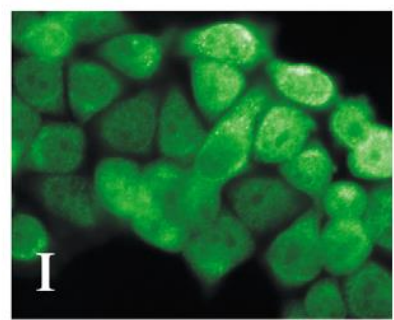

Bax

Figure 2: Effect of antioxidant on Bax and cytochrome c localization in HeLa cells undergoing TNF- $\alpha$-induced apoptosis.

Cells treated with E/TNF ( $5 \mathrm{ng} / \mu \mathrm{l}$ of TNF- $\alpha$ plus $1 \mu \mathrm{g} / \mathrm{ml}$ of emetine) for $6 \mathrm{~h}$ in the absence (A-C) or presence $300 \mu \mathrm{M}$ DEVD-cho (D-F) or $200 \mu \mathrm{M}$ BHA (G-I) were double immunostained for cytochrome c (B, D and H) and Bax (C, F and I). Nuclei were visualized by Hoechst 33258. Arrows indicate apoptotic cells. DEVD-cho is an inhibitor of executing caspases. BHA is a potent antioxidant (similar results are obtained with other antioxidants, such as NDGA). The Bax N20 pAb (Santa Cruz biotechnology) was used in all cases. 
a)
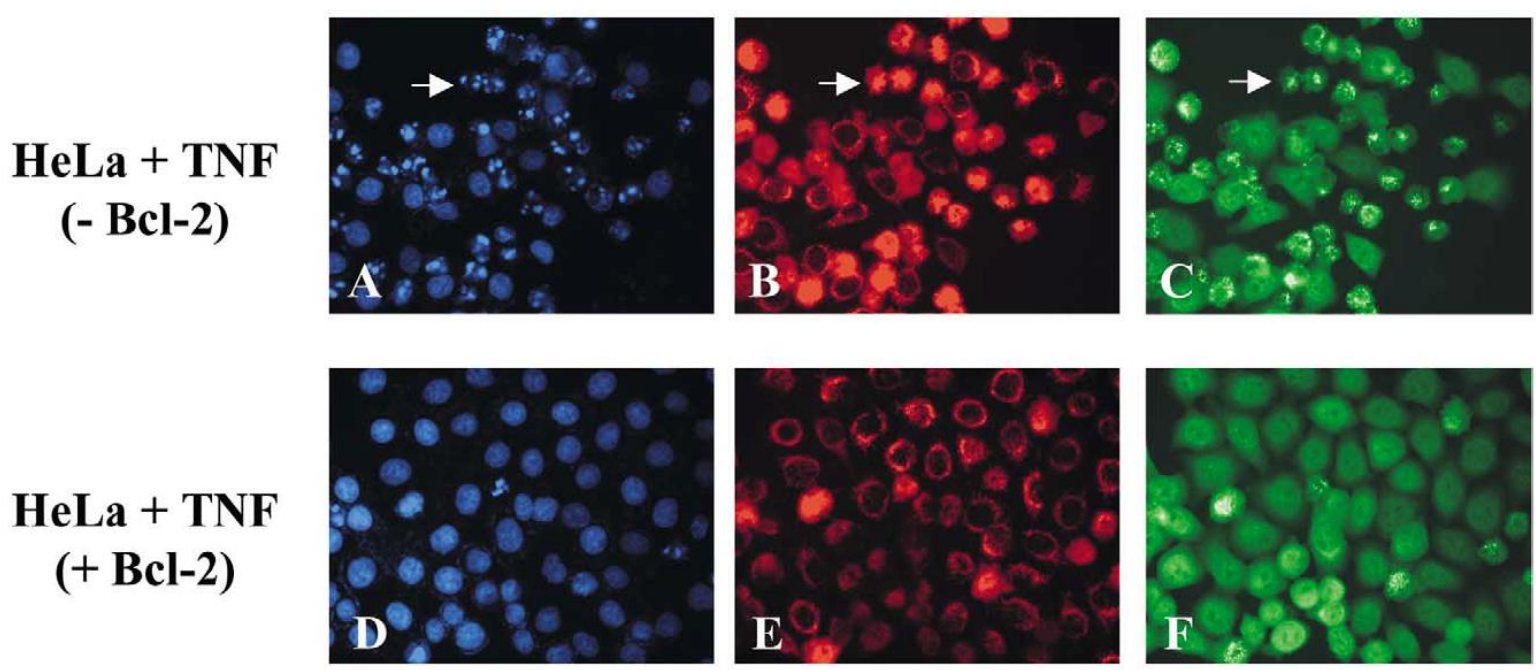

Hoechst

cytochrome c

Bax

b)

- Bcl-2

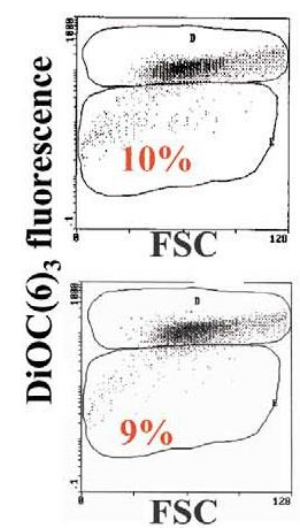

Control
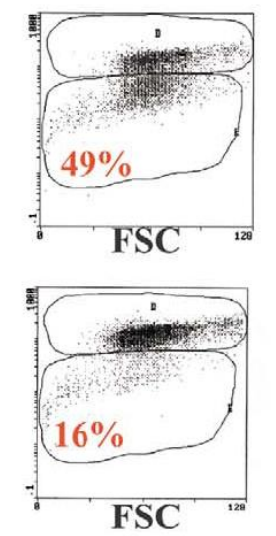

E/TNF

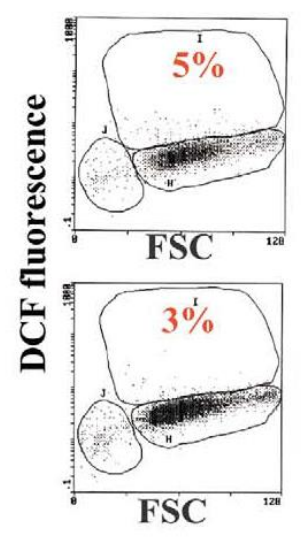

Control

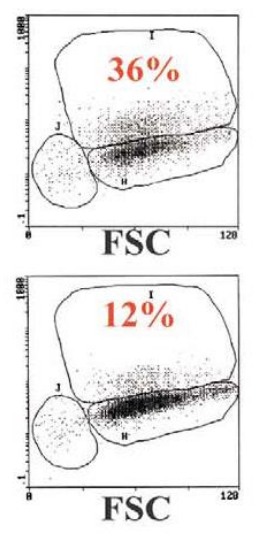

E/TNF

Figure 3: Effect of Bcl-2 on mitochondrial events occurring during TNF- $\alpha$-induced apoptosis of HeLa cells.

Part a: Effect of Bcl-2 on the mitochondrial membrane potential and ROS accumulation. Panels depict typical cytograms (FSC versus fluorescence) obtained with flow cytometric analysis of Control or E/TNF treated HeLa cells that overexpress (bottom) or not $b c l-2$ (top). The mitochondrial membrane potential, measured by the $\mathrm{DiOC}_{6}(3)$ fluorescence (left panel), and the ROS production, measured by the DCF fluorescence (right panel), are reported. Values of FSC (Forward angle Scatter) correlate to the size of the cells.

Part b: Effect of Bcl-2 on Bax and cytochrome c localization in cells undergoing TNF$\alpha$-induced apoptosis. HeLa cells overexpressing (D-F) or not (A-C) a tetracycline-regulated inducible $b c l-2$ gene were treated with E/TNF for $6 \mathrm{~h}$. Cells were double immunostained for cytochrome c (B, D and H) and Bax (C, F and I), and nuclei were visualized by Hoechst 33258. Arrows indicate apoptotic cells. 


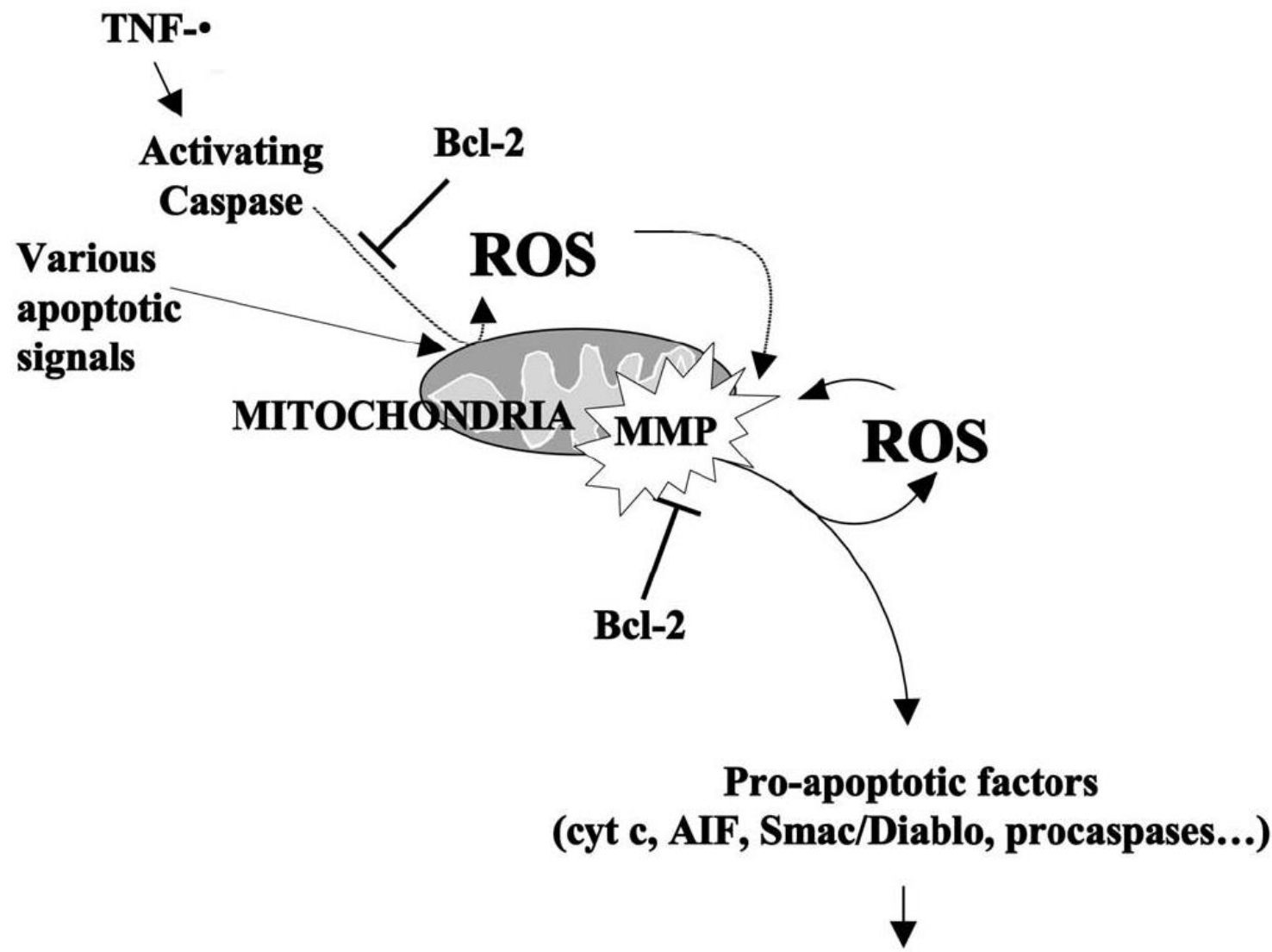

Apoptosis

Figure 4: Schematic model of the roles of mitochondrial ROS in apoptosis

Numerous signals can lead to apoptosis and the induction pathways seem to converge to events leading to an increase in mitochondrial membranes permeability (MMP) and the release of pro-apoptotic factors from the mitochondria. Before these events, in response to numerous apoptosis inducers, among which $\mathrm{TNF}-\alpha$, mitochondrial ROS production can contribute to apoptosis signaling during the induction phase. ROS accumulate as a result of a dysfunction in the mitochondrial respiratory chain. ROS also intervene in later steps in an amplifying loop, acting on mitochondrial membrane permeability, and contributing then to the activation of execution caspase. 